\title{
Non-tumoural aqueduct stenosis and normal pressure hydrocephalus in the elderly
}

\author{
JAN VANNESTE, RON HYMAN \\ From the Department of Neurology, Sint Lucas Ziekenhuis, Amsterdam, and the Department of Biological \\ Psychiatry, University Hospital, Utrecht, The Netherlands
}

SUMMARY From 1981 to 1985 a prospective study on normal pressure hydrocephalus was performed. One of the aims of this study was to determine the site of CSF obstruction. Among 17 consecutive patients with a tentative diagnosis of normal pressure hydrocephalus, nine appeared to have non-communicating hydrocephalus most probably due to primary non-tumoural aqueduct stenosis. This unexpected finding provides evidence that non-tumoural aqueduct stenosis is a frequent cause of normal pressure hydrocephalus in older patients. Some clinical, aetiological and therapeutic aspects in this particular subgroup are discussed.

Normal pressure hydrocephalus is a syndrome combining the non-specific clinical triad of gait instability, mild to moderate mental deterioration and occasionally urinary incontinence with chronic hydrocephalus and normal CSF pressure at random lumbar punctures. ${ }^{1-3}$ This syndrome is known to occur in both non-communicating and communicating hydrocephalus, ${ }^{14-6}$ but most articles on normal pressure hydrocephalus deal with communicating hydrocephalus, of known or unknown aetiology.

Reports on normal pressure hydrocephalus infrequently implicate non-tumoural aqueduct stenosis as the cause of the syndrome and major review articles on adult non-tumoural aqueduct stenosis rarely mention older patients with normal pressure hydrocephalus. ${ }^{7-19}$

After having encountered a number of patients presenting with normal pressure hydrocephalus due to non-tumoural aqueduct stenosis, we performed a prospective study from January 1981 to January 1985 on all patients presenting with a potential normal pressure hydrocephalus syndrome, diagnosed on the basis of clinical criteria, CT characteristics and normal CSF pressures at random lumbar puncture. Seventeen patients met the criteria and nine appeared to have normal pressure hydrocephalus due to aqueduct

Address for reprint requests: Dr JAL Vanneste, Sint Lucas Ziekenhuis, Jan Tooropstraat 164, 1061 AE Amsterdam, The Netherlands.

Received 6 June 1985 and in revised form 29 August 1985. Accepted 21 September 1985 stenosis. All of these were aged 60 years or over. This particular group is discussed.

\section{Patients}

The clinical profile was similar in all patients and is summarised in table 1. Two illustrative cases are briefly described.

Case 2 A 69-year-old man complained of slight gait difficulties for one year. Neurological examination disclosed bilateral pyramidal tract involvement, decreased vibration sense in the legs and gait imbalance. CT scans with and without contrast enhancement and metrizamide cisternography showed marked internal hydrocephalus consistent with non-tumoural aqueduct stenosis. Cisternography with radioactive labelled human albumin was normal. A neurosurgical procedure was refused by the patient but four months later further mental deterioration and increasing gait instability led to ventriculoatrial shunting, resulting in marked improvement. His neurological condition remained stable until he died 18 months later following the complications of an oat-cell bronchus carcinoma. A CT brain scan and lumbar puncture one month before his death failed to demonstrate intracranial metastases.

Case 5 A 62-year-old woman presented in December 1983 with gait instability, propulsion and excessive muscular fatiguability in the legs. The medical history revealed a bacterial meningitis at the age of 8 years. Neurological findings consisted of slight hypokinesia, hyperreflexia, a bilateral extensor plantar response and gait imbalance. A CT brain scan showed marked internal hydrocephalus with a normal fourth ventricle. Two lumbar punctures disclosed normal CSF pressures. Metrizamide cisternography was characterised by filling of the fourth ventricle and absence of contrast at the convexity. RIHSA cisternography was normal except 
Table 1 Clinical data

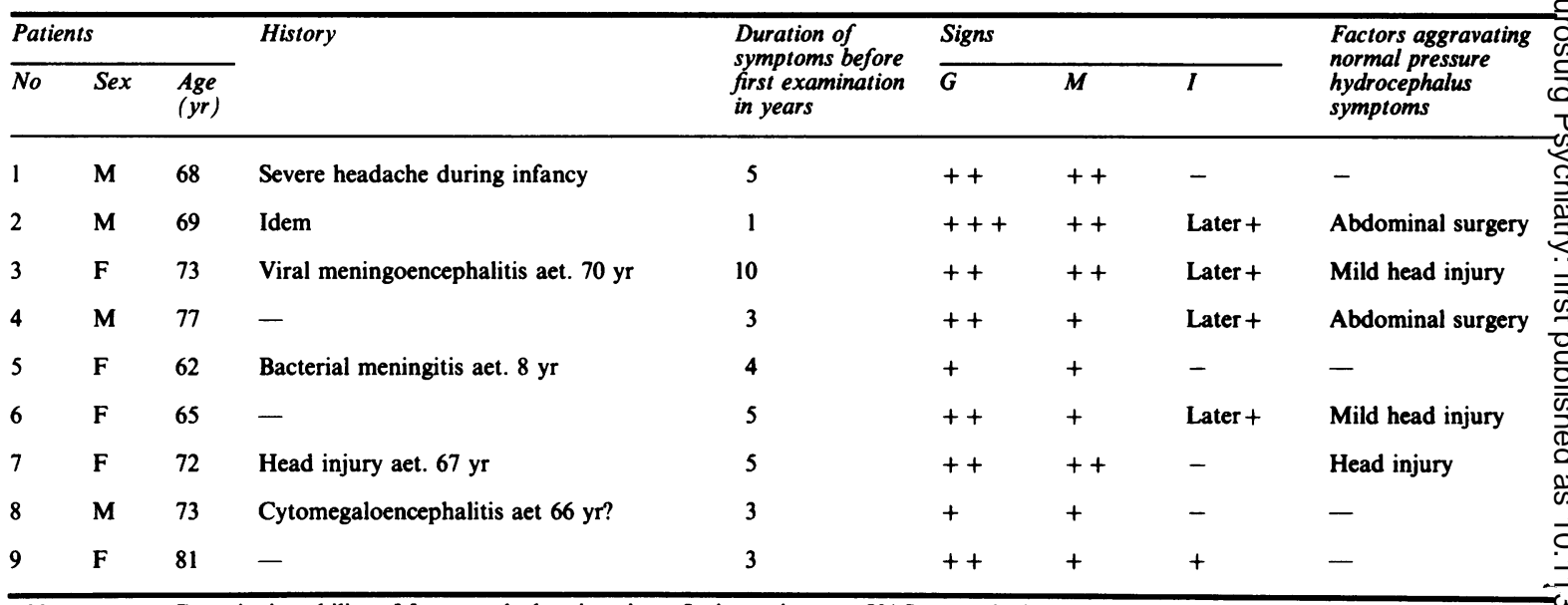

Abbreviations: G, gait instability; M, mental deterioration; I, incontinence; VAS, ventriculoatrial shunting; ( - ), absent; ( \pm ), fluctuating: $\sigma$ $(+)$, slight; $(++)$, moderate; $(+++)$, marked.

for slightly prolonged stasis of the isotope at the convexity. Non-tumoural aqueduct stenosis as the cause of this normal pressure hydrocephalus appeared likely. Nine months later, gait imbalance increased and mental functions deteriorated further. Repeat removals of $30 \mathrm{ml} \mathrm{CSF}$ resulted in a slight improvement and relative clinical stabilisation.

\section{Methods}

The following examinations were performed: plain skull radiography and, when indicated, sellar tomography; electroencephalography; CT brain scan with and without contrast enhancement; measurements of the intracranial pressure by repeat lumbar punctures in a horizontal lateral decubitus position: a pressure of more than $200 \mathrm{~mm} \mathrm{H}_{2} \mathrm{O}$ was considered to be elevated; cisternography with both radioactive iodinized human serum albumin (RIHSA) and metrizamide in patients $1-5$ and with metrizamide alone in patients 6-9; quantitative evaluation of the hydrocephalus consisted of calculation of the ventricular size index (VSI) ${ }^{\mathbf{2 0}}$ and the maximal width of the third ventricle, the temporal horns and the fourth ventricle, measured in mms. The cortical sulci were evaluated as absent $(-)$, normal $(+)$ or enlarged $(++)$.

Lumbar CSF tap tests ${ }^{21}$ with removal of $30 \mathrm{ml} \mathrm{CSF}$ and quantitative evaluation of the effect on both motor and mental functions were performed in patients 3-9. Neuropsychological testing consisted of Luria's neuropsychological test battery ${ }^{22}$ and additional tests involving motor speed, attention, concept-shifting, visual scanning and memory processes. ${ }^{23}$

The criteria of failure were that normal pressure hydrocephalus due to aqueduct stenosis patients scored at or below the tenth percentile of an age-matched normative group. Serial psychometric testing and CT scanning were used for both evaluation of progression and postoperative course.

There were no facilities for cerebral blood-flow measurements before and after CSF removal. More invasive diagnostic procedures such as prolonged intracranial pres- sure monitoring and CSF infusion tests were not performed either because they were refused by the patients or their family or because these investigations were considered not to influence substantially therapeutic management.

CSF shunting was only offered to patients with a clear-cut clinical deterioration. It consisted of insertion of a ventriculoatrial shunt with a Holter medium-pressure valve. The effect of surgery was evaluated by subjective evaluation of improvement (opinion of the patient, his family and the nursing staff) and by serial quantitative functional and neuropsychological parallel testing. In two patients an additional ventriculography with metrizamide was performed (cases 2 and 7).

\section{Results}

The most important additional investigations are listed in table 2.

CT scans of the brain showed markedly dilated lateral and third ventricles and a normal fourth ventricle. The VSI ranged between 0.45 and 0.65 but eight of the nine patients had a VSI greater than 0.53. Repeat lumbar punctures in each case yielded pressures between $140-190 \mathrm{~mm} \mathrm{H}_{2} \mathrm{O}$. In patients 1-5 RIHSA cisternography showed no ventricular reflux, a normal passage through the basal cisterns and normal or minimal slowing of the isotope clearance at the convexity. In patients $2-9$ the metrizamide cisternography showed a normal configuration of the basal cisterns, filling of the fourth ventricle and no contrast in the third ventricle. In two patients the metrizamide failed to migrate sufficiently to the convexity (cases 4 and 5) but in these patients additional RIHSA scans showed sufficient convexity flow with only slight slowing of CSF resorption. In these cases the metrizamide cisternographies provided inadequate information. 




The predictive value of the CSF tap tests was disappointing: from the five operated patients in whom the test was performed, three tests were false negative, one false positive and one equivocal. Repeat CSF removals in two unoperated patients yielded stabilisation in one and persisting amelioration in the other patient.

The neuropsychological investigations showed a profile as described in the so-called "hydro-dynamic dementia". ${ }^{24}$ Minimal disturbances of the higher cortical functions contrasted with a significant deterioration on tests measuring motor speed, concept shifting, verbal memorising and delayed recall.

Ventricular shunting was offered to the patients with clinical progression, documented either by the history or by serial clinical and neuropsychological testing. The results of surgery are documented in table 2.

\section{Discussion}

One of the aims of our study was to investigate the incidence of non-tumoural aqueduct stenosis in normal pressure hydrocephalus. The nine described patients conformed with the clinical criteria of normal pressure hydrocephalus and the CT brain scans suggested hydrocephalus due to non-tumoural aqueduct stenosis. Arguments to perform additional neuroradiological investigations were that in communicating hydrocephalus the fourth ventricle may

Table 2 Investigations and postoperative course

\begin{tabular}{|c|c|c|c|c|c|c|c|c|c|c|}
\hline \multicolumn{3}{|c|}{ Patient } & \multicolumn{2}{|l|}{ CT scan } & \multirow{2}{*}{$\begin{array}{l}\text { Metrizamide } \\
\text { scan }\end{array}$} & \multirow[t]{2}{*}{ RIHSA scan } & \multicolumn{2}{|c|}{ Influence of CSF tap test } & \multicolumn{2}{|c|}{ Postoperative improvement } \\
\hline$\overline{N o}$ & $\begin{array}{l}\text { Age } \\
(y r)\end{array}$ & $\overline{V S I}$ & $\begin{array}{l}\text { Temporal } \\
\text { horns } \\
\text { enlargement }\end{array}$ & $\begin{array}{l}\text { Cortical } \\
\text { sulci } \\
\text { enlargement }\end{array}$ & & & $\bar{G}$ & $M$ & $\bar{G}$ & $M$ \\
\hline 1 & 68 & 0.60 & + & + & $\begin{array}{l}\text { AS } \\
\text { CF:N }\end{array}$ & $\mathbf{N}$ & $\mathrm{np}$ & np & + & + \\
\hline $\begin{array}{l}2 \\
3 \\
4\end{array}$ & $\begin{array}{l}69 \\
73 \\
77\end{array}$ & $\begin{array}{l}0.63 \\
0.53 \\
0.52\end{array}$ & $\begin{array}{l}++ \\
+ \\
+\end{array}$ & $\begin{array}{l}+ \\
+ \\
+\end{array}$ & $\begin{array}{l}\text { AS, CF:N } \\
\text { AS, CF:N } \\
\text { AS } \\
\text { CF:minimal }\end{array}$ & $\begin{array}{l}\mathbf{N} \\
\mathbf{N} \\
\mathbf{N} \text { except minimally } \\
\text { delayed resorption }\end{array}$ & $\begin{array}{l}\text { np } \\
\mathbf{O} \\
\mathbf{O}\end{array}$ & $\begin{array}{l}\text { np } \\
+ \\
+\end{array}$ & $\begin{array}{l}+++ \\
+++ \\
+++\end{array}$ & $\begin{array}{l}+++ \\
+++ \\
++\end{array}$ \\
\hline 6 & 65 & 0.55 & + & $\mathbf{O}$ & $\begin{array}{l}\text { AS } \\
\text { CF:N }\end{array}$ & np & & + & ++ & +++ \\
\hline $\begin{array}{l}7 \\
8\end{array}$ & $\begin{array}{l}72 \\
73\end{array}$ & $\begin{array}{l}0.53 \\
0.45\end{array}$ & $\stackrel{+}{0}^{+}$ & + & $\begin{array}{l}\text { AS, CF:N } \\
\text { AS, CF:N }\end{array}$ & $\begin{array}{l}n p \\
n p\end{array}$ & $\stackrel{+}{0}$ & $\stackrel{+}{0}^{+}$ & $\begin{array}{l}\text { O } \\
++\end{array}$ & $\begin{array}{l}0 \\
+++\end{array}$ \\
\hline 9 & 81 & 0.57 & ++ & + & AS, CF:N & np & $\mathbf{0}$ & $\mathbf{0}$ & No shunt & \\
\hline
\end{tabular}

Abbreviations: VSI, ventricular size index; CF, convexity flow; AS, aqueduct stenosis; np, not performed; N, normal; O, no; + , slight; ++ , moderate; +++ , marked. 

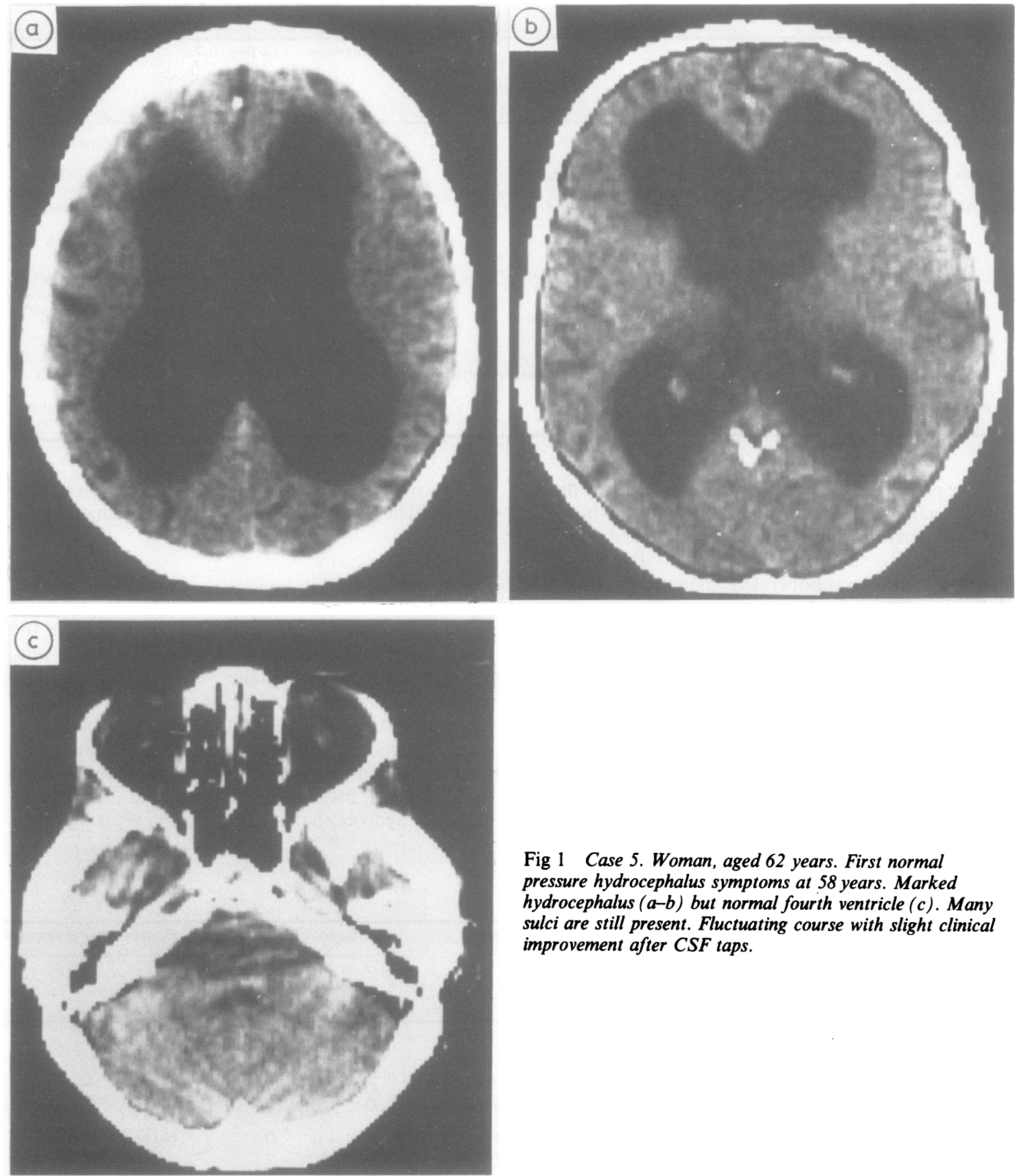

appear normal on CT brain scans ${ }^{25-27}$ and that the site of CSF flow obstruction may be situated at more than one level. Furthermore, our need to ascertain the presence of non-tumoural aqueduct stenosis was sup-
Fig 1 Case 5. Woman, aged 62 years. First normal pressure hydrocephalus symptoms at 58 years. Marked hydrocephalus $(a-b)$ but normal fourth ventricle $(c)$. Many sulci are still present. Fluctuating course with slight clinical improvement after CSF taps.

ported by Messert's statement that in the problem of "occult" normal pressure hydrocephalus, an aqueduct stenosis might play a greater role than commonly presumed. ${ }^{28}$ 

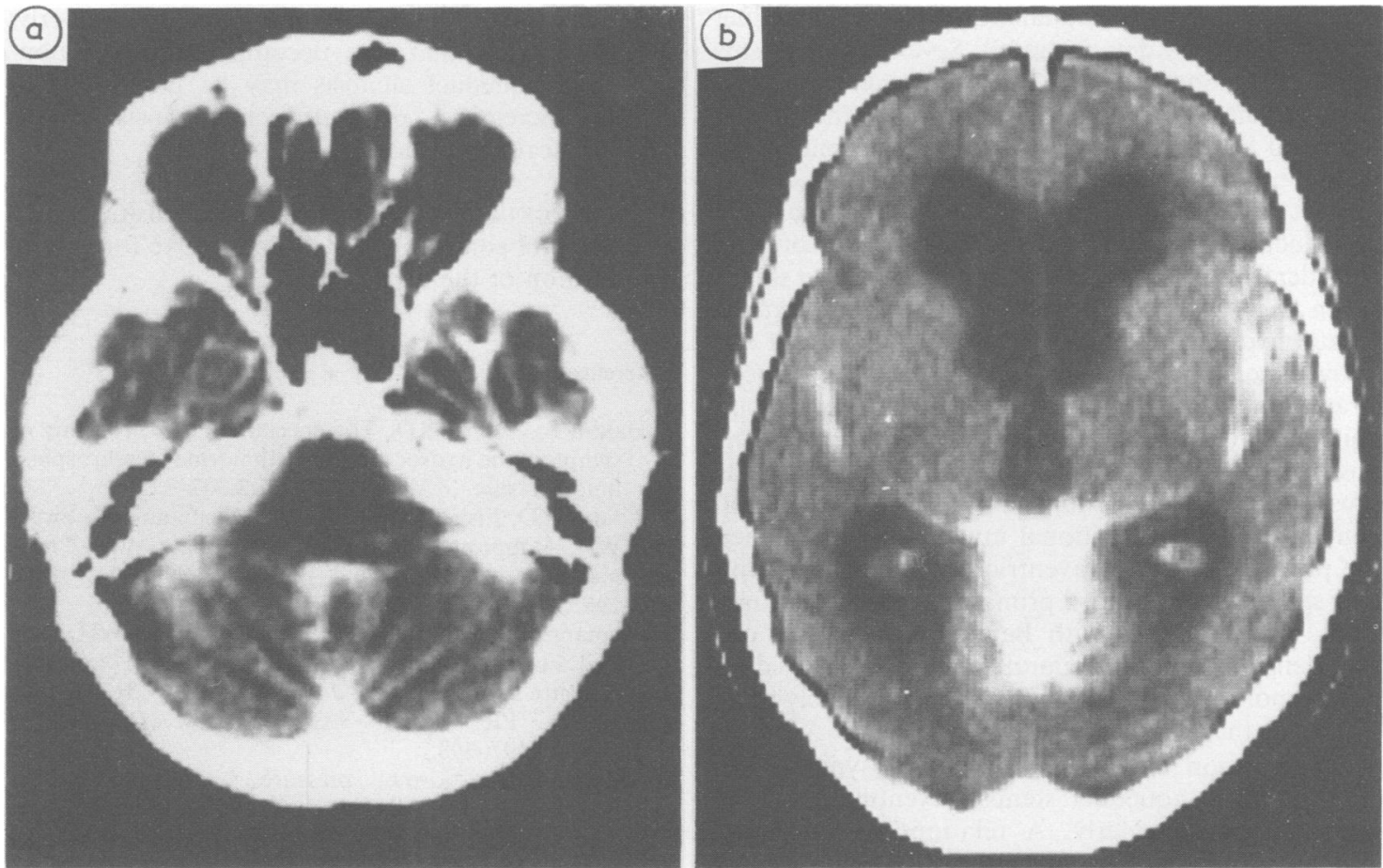

Fig 2 Case 6. Woman, aged 65 years. Cisternography one hour after lumbar introduction of metrizamide. (a) filling of the fourth ventricle, $(b)$ absence of contrast in the third ventricle; metrizamide has already reached the Sylvian fissures.

In our series non-tumoural aqueduct stenosis was confirmed by an additional metrizamide ventriculography in only two cases. Nevertheless we considered the presence of non-tumoural aqueduct stenosis as highly probable: the fourth ventricle was normal in contrast to markedly enlarged lateral and third ventricles; in spite of this ventriculomegaly, no metrizamide migrated from the fourth to the third ventricle, suggesting an aqueductal block. Finally, the demonstration of an unimpaired CSF flow from the basal cisterns to the convexity excluded an extraventricular CSF block as the cause of chronic hydrocephalus.

Non-tumoural aqueduct stenosis is a common cause of chronic hydrocephalus in children but it occurs less frequently later in life. ${ }^{29-31}$ In adults the average age of non-tumoural aqueduct stenosis lies between $20-40$ years. $^{8-18}$ The occurrence of symptomatic non-tumoural aqueduct stenosis in older patients has rarely been quoted: we were therefore surprised to find nine such cases among a series of 17 consecutive patients with a potential normal pressure hydrocephalus seen within 4 years. Clinically they confirmed previous experiences that when nontumoural aqueduct stenosis decompensates in the elderly it usually does so in a normal pressure hydrocephalus fashion. ${ }^{12131730}$ In the same period, no per- sons aged 60 years or older with non-tumoural aqueduct stenosis and increased intracranial pressures were met.

Speculations and controversies concerning the origin of non-tumoural aqueduct stenosis have been extensively reviewed. ${ }^{15293132}$ Congenital aqueductal malformations, post-infectious periaqueductal gliosis or the combination of both factors have been demonstrated as the cause. In our patient group three had possible congenital non-tumoural aqueduct stenosis as they underwent medical treatment during their infancy for prolonged and intractable headache and in three others an infectious factor may have played a role in the origin or further progression of the aqueduct of Sylvius (see table 1). However, the lack of anatopathological confirmation does not exclude the presence of small and slow growing periaqueductal microgliomas, which ultimately appeared to be the unexpected (but very rare) cause of a chronic noncommunicating hydrocephalus attributed to nontumoural aqueduct stenosis during life. ${ }^{9151631}$

The question of secondary or "functional" aqueduct stenosis has been a matter of debate. Williams ${ }^{33}$ and McMillan ${ }^{17}$ state that there is no proven basis for the assumption that aqueduct stenosis precedes hydrocephalus, arguing that in some patients with 
communicating hydrocephalus a secondary aqueduct stenosis has been demonstrated. Several mechanisms have been proposed to explain a functional aqueduct stenosis: mesencephalic compression by the dilated temporal horns ${ }^{33}$ or downward displacement of the upper brainstem with aqueductal kinking and/or obstruction. ${ }^{1134}$ Williams' arguments for a secondary aqueduct stenosis were mainly based on theoretical considerations, on cases of functional aqueduct stenosis in high-pressure hydrocephalus and on experimental hydrocephalus in animals. To the best of our knowledge, such mechanisms have not been demonstrated in normal pressure hydrocephalus due to aqueduct stenosis and seem improbable in view of the absence of substantial elevation of intraventricular pressures. Although our cases lack pathological confirmation, the additional investigations excluded the presence of an extraventricular CSF obstruction and strongly suggested a primary aqueduct stenosis. Thus, in accordance with Bennett's findings, ${ }^{14}$ our experience with non-tumoural aqueduct stenosis does not support the hypothesis that it is more likely to be the result than the cause of hydrocephalus.

The question remains why a life-long asymptomatic non-tumoural aqueduct stenosis eventually decompensates in the elderly. A relationship with cerebrovascular disease as suggested in communicating normal pressure hydrocephalus ${ }^{35-37}$ was not evident as only two patients had clinical symptoms of vascular disease.

In non-tumoural aqueduct stenosis, one of the contributing factors may be the following: it has been illustrated pathologically that in all forms of chronic hydrocephalus there is severe ependymal disruption and secondary subependymal gliotic reaction. ${ }^{29} 38$ We speculate that in some of our cases an increasingly narrowed aqueduct by ependymal granulation ${ }^{3940}$ may have finally led to functionally aqueduct incompetence.

When surgery is considered in symptomatic nontumoural aqueduct stenosis, ventriculoatrial or ventriculoperitoneal shunting is usually performed. ${ }^{41}$ However, renewed interest has been paid to internal CSF diversion procedures including third ventriculostomy and aqueductal cannulation. ${ }^{4243}$ When internal shunting is planned, a coexisting subarachnoïdal CSF obstruction must be ruled out. Dynamic cisternography with a water-soluble nonionized contrast material ${ }^{4445}$ and/or with an isotope seems a more suitable technique than reliable but more invasive and quite complex lumboventricular CSF infusion tests. ${ }^{46}$

In conclusion, our study reveals that non-tumoural aqueduct stenosis may be a frequent cause of normal pressure hydrocephalus in older patients and that a "silent" hydrocephalus due to non-tumoural aque- duct stenosis may become symptomatic in the elderly. The suggestion that late decompensation in nontumoural aqueduct stenosis may be partly due to slowly increasing periaqueductal gliosis awaits pathological confirmation.

The authors thank Gareth Davies and Ben Ansink for their helpful comments and Wilma Stoke for careful preparation of the manuscript.

\section{References}

${ }^{1}$ Hakim S, Adams RD. The special clinical problems of symptomatic hydrocephalus with normal cerebrospinal fluid pressure. J Neurol Sci 1965;2:307-27.

${ }^{2}$ Adams RD, Fisher CM, Hakim S, Ojemann RG, Sweet WH. Symptomatic occult hydrocephalus with "normal" cerebrospinal fluid pressure. $N$ Engl J Med 1965;273:117-26.

${ }^{3}$ Ojemann RG, Fisher CM, Adams RD, Sweet WH, New PFJ. Further experience with the syndrome of "normal" pressure hydrocephalus. $J$ Neurosurg 1969;31:279-94.

${ }^{4}$ McHugh PR. Occult hydrocephalus. $Q \quad J \mathrm{Med}$ 1964;33:297-308.

${ }^{5}$ Katzman R. Normal pressure hydrocephalus. In: Katzman R, Terry RD, Bick KL. Alzheimer's Disease: Senile Dementia and Related Disorders. Aging 1978;7:115-24.

${ }^{6}$ Huckman MS. Normal pressure hydrocephalus: evaluation of diagnostic and prognostic tests. $A J N R$ 1981;2:385-95.

${ }^{7}$ Pickard JD. Normal pressure hydrocephalus - to shunt or not to shunt. In: Warlow C, Garfield J, eds. Dilemmas in the Management of the Neurological Patient. Edinburgh: Churchill Livingstone, 1984:207-14.

${ }^{8} \mathrm{Nag} \mathrm{KT}$, Falconer MA. Non-tumoural stenosis of the aqueduct in adults. $\mathrm{Br}$ Med $J$ 1966;2:1168-70.

${ }^{9}$ Schechter MM, Zingesser LH. The radiology of aqueductal stenosis. Radiology 1967;88:905-16.

${ }^{10}$ Table Ronde sur l'hydrocéphalie chronique non-tumorale de l'adulte. Neurochirurgie 1976;22:101-216.

11 Jakubowski S, Jefferson A. Axial enlargement of the third ventricle and displacement of the brain-stem in benign aqueduct stenosis. J Neurol Neurosurg Psychiatry 1972;35:114-23.

${ }^{12}$ Harrison MJG, Robert CM, Uttley D. Benign aqueduct stenosis in adults. J Neurol Neurosurg Psychiatry 1974;37:1322-8.

${ }^{13}$ Little JR, Wayne Houser O, McCarthy CS. Clinical manifestations of aqueductal stenosis in adults. $J$ Neurosurg 1975;43:546-52.

${ }^{14}$ Bennett RT, Allen PBR, Miller JDR. Non-tumoral stenosis of the aqueduct in adults. Surg Neurol 1975;4:523-7.

${ }^{15}$ Visot A, Cophignon J, George B, Philippon J. Sténose de l'aqueduc chez l'adulte. Neurochirurgie 1976;22:118-24.

${ }^{16}$ Balakrishnan V, Dinning TAR. Non-neoplastic stenosis of the aqueduct presenting in adolescence and adult life. Surg Neurol 1977;7:333-8.

${ }^{17}$ McMillan JJ, Williams B. Aqueduct stenosis. J Neurol Neurosurg Psychiatry 1977;40:521-32. 
${ }^{18}$ Lapras CL, Bret Ph. Les Sténoses de l'aqueduc de Sylvius. Société de Neurochirurgie de Langue Française. Neurochirurgie 1980;26:33-71.

${ }^{19}$ Lobato RD, Lamas E, Esparza J, Portillo JM, Rivas J. Intraventricular pressure monitoring and CSF dynamics in non-tumoral aqueduct stenosis. In: Shulman $\mathbf{K}$, Marmaroy A, Miller JD, Becker DP, Hochwald G, Brock M, eds. Intracranial Pressure IV Berlin. 1980:511-3.

${ }^{20}$ Ter Brugge KG, Rao KC. Hydrocephalus and atrophy. In: Lee SH, Rao KC, eds. Cranial Computed Tomography. New York: McGraw Hill, 1983:171-200.

${ }^{21}$ Wikkelsø C, Anderson H, Blomstrand C, Lindquist G. The clinical effect of lumbar puncture in normal pressure hydrocephalus. J Neurol Neurosurg Psychiatry 1982;45:64-9.

${ }^{22}$ Christensen AL. Luria's Neuropsychological Investigation. Copenhagen: Munksgaard, 1979.

${ }^{23}$ Lezak MD. Neuropsychological Assessment. New York: Oxford University Press, 1976.

${ }^{24}$ Crockard HA, Hanlon K, Duda EE, Mullan JF. Hydrocephalus as a cause of dementia: evaluation by computerised tomography and intracranial pressure monitoring. J Neurol Neurosurg Psychiatry 1977;40:736-40.

${ }^{25}$ Gado MH, Coleman RE, Lee KS, Mikhael MA, Alderson PO, Archer CR. Correlation between computed transaxial tomography and radionuclide cisternography in dementia. Neurology (Minneap) 1976;26:555-60.

${ }^{26}$ Jacobs L, Kinkel W. Computerized axial transverse tomography in normal pressure hydrocephalus. Neurology (Minneap) 1976;26:501-7.

${ }^{27}$ Gunasekera L, Richardson AE. Computerized axial tomography in idiopathic hydrocephalus. Brain 1977;100:749-54.

${ }^{28}$ Messert B, Wannamaker BB. Reappraisal of the adult occult hydrocephalus syndrome. Neurology (Minneap) 1974;24:224-31.

${ }^{29}$ Russell DS. Observations on the Pathology of Hydrocephalus. Medical Research Council. Special Report Series. No. 265. London, H.M. Stationary Office, 1949.

${ }^{30}$ Jensen F, Jensen FT. Acquired hydrocephalus. A clinical analysis of 160 patients studied for hydrocephalus. Acta Neurochir (Wein) 1979;46:119-33.

${ }^{31}$ Salam MZ. Stenosis of the aqueduct of Sylvius. In: Vinken PJ, Bruyn GW. Congenital Malformations of the Brain and Skull. Handbook of Clinical Neurology vol. 30. North-Holland Publ. Co, Amsterdam, 1977:609-22.
${ }^{32}$ Greitz T, Levander BE, Lopez J. High blood pressure and epilepsy in hydrocephalus due to stenosis of the aqueduct of Sylvius. Acta Neurochirurg 1971;24:201-6.

${ }^{33}$ Williams B. Is aqueduct stenosis a result of hydrocephalus? Brain 1973;96:399-412.

${ }^{34}$ Nugent GR, Al-Mefty O, Chou S. Communicating hydrocephalus as a cause of aqueductal stenosis. $J$ Neurosurg 1979;51:812-8.

${ }^{35}$ Mathew NT, Meyer JS, Hartmann A. Abnormal cerebrospinal fluid and blood flow dynamics. Arch Neurol 1975;32:657-64.

${ }^{36}$ Earnest MP, Fahn S, Karp JH, Rowland LP. Normal pressure hydrocephalus and hypertensive cerebrovascular disease. Arch Neurol 1974;31:262-6.

${ }^{37}$ Koto A, Rosenberg GA, Horoupian R. Syndrome of normal pressure hydrocephalus: possible relation to hypertensive and arteriosclerotic vasculopathy. J Neurol Neurosurg Psychiatry 1977;40:73-9.

${ }^{38}$ Milhorat TH. Hydrocephalus and the cerebrospinal fluid. Baltimore: Williams and Wilkins Co, 1972:135-70.

${ }^{39}$ Petit-Dutaillis D, Thiébaut F, Berdet H, Barbizet J. A propos des sténoses de l'aqueduc de Sylvius d'origine non tumorale de l'adolescent et de l'adulte. Rev Neurol (Paris) 1950;82:417-21.

${ }^{40}$ Ribadeau-Dumas JL, Ricou P, Verdure L, Rondot P, Escouroll R. Etude anatomique d'une hydrocéphalie à pression normale. Neurochirurgie 1976;22:138-45.

${ }^{41}$ Illingworth RD, Loque V, Symon L, Uemura K. The ventriculocaval shunt in the treatment of adult hydrocephalus: results and complications in 101 patients. $J$ Neurosurg 1971;35:681-5.

${ }^{42}$ Foltz EL, Aine C. Diagnosis of hydrocephalus by CSF pulse-wave analysis. A clinical study. Surg Neurol 1981;15:283-93.

${ }^{43}$ Bret J. Recanalization of Sylvian Aqueduct. Europ $J$ Radiol 1981;1:67-70.

${ }^{44}$ Drayer BP, Rosenbaum AE, Higman HB. Cerebrospinal fluid imaging using serial metrizamide CT cisternography. Neuroradiology 1977;13:7-17.

${ }^{45}$ Kobayashi N, Saito Y, Miyashita T, Tajika Y. Cisternography of the posterior fossa with metrizamide. Radiology 1981;141:819-21.

${ }^{46}$ Magnaes B. Cerebrospinal fluid hydrodynamics in adult patients with benign non-communicating hydrocephalus: one-hour test shunting and balanced CSF infusion test to select patient for intracranial bypass operation. Neurosurgery 1982;11:769-75. 